\title{
Needle-free Injector
}

National Cancer Institute

\section{Source}

National Cancer Institute. Needle-free Injector. NCI Thesaurus. Code C149699.

Device for injecting a medicinal product, usually a liquid, by means of high pressure without a needle, through the skin barrier. 